\title{
The intended perception of the Imperial Gardens of Chengde in $I 780^{\mathrm{I}}$
}

\section{PHILIPPE FORET}

Record Written by the Emperor on the Mountain Manor to Escape the Heat

From Gold Mountain (Jin Shan) a vein in the earth broke through, and from the hot water was formed a spring [Rehe river spring]. The clouds [of steam] forever filling the valley, the stones and pools turn green. Grass grows luxuriantly everywhere, and there is no fear that harm will come to one's fields or home. The wind is pure, and the summers are cool, easily suiting and nourishing people. ... Then there is this place, Rehe (Chengde). The road is close to the capital (Beijing), and to go back and forth takes less than two days. The land is spread out, wild and untilled. If you fill your mind with it, a myriad cares cannot but be driven away. When from here (Bi Shu Shan Zhuang) you weigh the appearance of high and low, far and near, the views of the mountains and peaks open themselves up before you. If you make your abode by a pine tree, the colors of the uneven riverbank (Rehe river) appear strikingly. If you lead water down to the pavilions, the fragrance of the hazelnut trees fills the valley. All this is not within the power of man to make. He can [only] move to an attractive place and adapt to it. Nothing has been squandered on carving the poles of my tent; one is content in one's thoughts, having embraced the simplicity of the spring and the forests. Looking peacefully at the myriad things, contemplating deeply their every type, one cannot escape enjoying the colorful birds and the green water. ... Written in the last decade of the sixth month of the fiftieth year of Universal Peace. ${ }^{2}$

\section{The gardens of Chengde}

The 'Record Written by the Emperor on the Mountain Manor to Escape the Heat' is a preface to an album of poems by the Qian Long Emperor (Qing Gaozong, r. I735-96) illustrated by a series of engravings of vistas.
The place described in this text is the $\mathrm{Bi}$ Shu Shan Zhuang (literally Mountain Manor to Escape the Heat) where the Kang Xi Emperor of the Great Qing (I644-I9II) and his grandson, the Qian Long Emperor, had a summer residence. Both emperors and their courts used to spend several months a year, usually between July and October, north of Beijing, in the cool Yanshan mountains. Chengde (literally Bearer of Virtue) is the name of the city where the Bi Shu Zhan Zhuang is located. Originally it was a hunting lodge called Rehe (literally Hot River) and later became a prefecture called Chengde (figure I). Chengde used to be the capital city of the province of Jehol and administered the part of Zhili that was north of the Great Wall of China. Located in what used to be Inner Mongolia, the city was built on land given by Mongols to the Kang Xi Emperor and garrisoned by Manchu and Mongol bannermen. The most prominent mountain island of the lake district of the Bi Shu Shan Zhuang is Jin Shan (literally Golden Mountain). Just north of Jin Shan lies the hot spring of Rehe, which the Kang Xi Emperor called a vein in the earth. In this paper, the 'residence gardens' refers to those of the $\mathrm{Bi}$ Shu Shan Zhuang only. The Chengde gardens include all the gardens of the mountain manor and its vicinity: the imperial gardens of the Bi Shu Shan Zhuang, the gardens of the Wai Ba Miao Temples (literally The Eight Outer Temples), those of the city of Chengde and, around the city, temples and residence, those in the countryside. I am enlarging the term 'garden' to accommodate temples because their courtyards have had gardens and their structures were located to enhance the landscape metaphors of Chengde.

Imperial gardens have formed a particularly rich medium for the geographical analysis of interactions of culture and place. Imperial gardens 


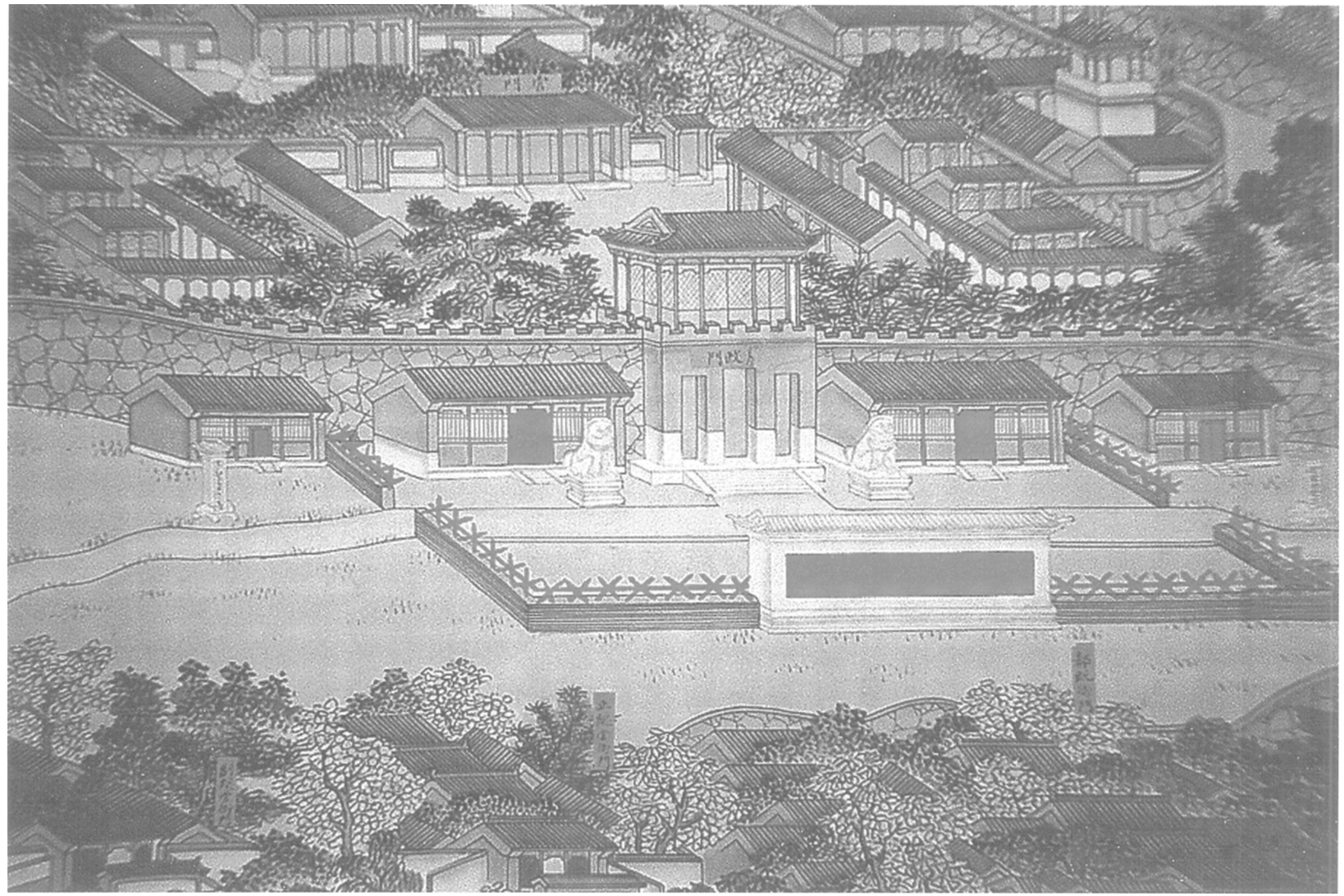

FIGURE I. Walls of Chengde and Main Gate of the Bi Shu Shan Zhuang; from Rehe xing gong quan tu (detail). Courtesy: Library of Congress. 
are élite gardens that often were designed according to a political strategy that aims at inspiring the deference, admiration and obedience of an audience of peers and vassals. Functionally speaking, the imperial gardens of the eighteenth-century courts were conceived to fulfill the monarchs agendas as they attempted to impress their subjects. This paper is intended as a contribution to the understanding of the limits of making a homology between all imperial gardens across eighteenth-century Eurasia, the comparability of which is assumed to be valid from a functional viewpoint. To analyse the relationship between imperial garden design and the political spectacle displayed by the Qing court, the ways in which visual depictions of gardens as cultural constructions have contributed to the representation of the environment as perceived by the Qing are examined. In the application of the methodology developed by recent scholarship for the study of garden history, I try to make use of contributions in landscape studies, ciltural geography and cartography to reveal the Qing ideology of garden representation. ${ }^{3}$ I discuss the function of gardens in the expansion of the Qing Empire and use as a case study the gardens of Chengde.

The Qian Long Emperor was the highest chief-editor of the Empire and for him the 'correct' representation of the garden architecture projects of the Bi Shu Shan Zhuang was a matter of public policy. His gardens were the topics of illustrations, poems and villas that conveyed information on what the perception of the gardens of Chengde was supposed to be at the time. Through these gardens the emperor imposed on the landscape of his domains a sense of continuity (by removing physical barriers from depictions of the gardens), and a sense of transition from a physical space into a metaphysical space (by maintaining a metaphorical connection between the cosmos and the empire). When the Qian Long Emperor's construction projects were completed, the resulting built landscape was replete with gardens that lead one to question the multifaceted relationship established between multicultural society and place. This paper has thus several objectives. Its main aim is to contribute to the analysis of visual documents relating to Chinese imperial gardens by focusing on the maps and paintings of Chengde c. I780. The year itself has no significance other than the one attached to the data of the compilation of several sources on Chengde that enables a comparative analysis of what Chengde was supposed to look like at the time. This analysis would ideally lead to the reconstruction of the wholeness and cohesion of the politics of garden design as perceived by the guests and visitors of these gardens. The focus of analysis would, therefore, also be actual historical subjects (Qian Long and his court) as implied readers and viewers. I also want to discuss the pictorial records of these gardens as images and maps that should be read in relation to the statements, silences, contradictions and distortions that reveal the Qian Long Emperor's apprehension of place. The images of the Chengde gardens assist the evaluation of the function of gardens in state building and help with the identification of coherent layers of information on landscape reading. The visual depictions and written records on the gardens of Chengde reveal the geographical and religious tools that the emperor employed to solve the difficulties inherent in assuming simultaneously the roles of Chinese emperor, Mongol khan and Buddhist divinity.

The representations of the Chengde gardens must be read carefully because they show meaningful discrepancies in the iconographic treatment of the place. The documents on Chengde that I shall examine are different in nature (maps, paintings, engravings of garden vistas, poems, built landscape) and access to them were originally restricted to certain audiences. Although they were made or printed in 1780 , not all the paintings, maps and vista drawings were made available to the contemporary visitors of the Bi Shu Shan Zhuang. Qian Long's guests were not in a position to be fully aware of discrepancies between actual and depicted landscape and between the different depictions of the same gardens. A second reason for close examination of the representations of the Bi Shu Shan Zhuang is that they are not only about the imperial gardens of Chengde: the gardens have to be considered in relational terms as they include landmarks and icons representative of other cultural landscapes. Chengde has a Potala temple, a Hangzhou-style Western Lake causeway, among other elements, and therefore cannot be seen as a simple self-contained place with definite boundaries. A third reason to justify this analysis is that neither the two paintings of the Library of Congress nor the maps of the Chengde Gazetteer (Chengde fu zhi) I am focussing on have been studied before (the Tai wan di li tu was actually miscatalogued). Because no scholar has attempted to compare the visual materials on Chengde, I cannot benefit from the insights of predecessors. My biggest regret is the almost total lack of records left by the guests and visitors at Qian Long court since the absence of records can only allow one to speculate on the landscape perception intended by the emperor for his audience. I cannot claim to be in position to discuss garden design as experienced by contemporary observers, 


\section{STUDIES IN THE HISTORY OF GARDENS AND DESIGNED LANDSCAPES : FORET}

as their perceptions have not been documented. At the same time, this should not lead one to neglect the audience's perspective that the Qian Long Emperor had in mind when he directed the construction and representation of the gardens of Chengde.

\section{Garden and representation}

In the period leading to 1780 , the Qian Long Emperor enlarged the summer capital of Chengde to create visual support to his claims to legitimacy in Tibet, Outer Mongolia and Eastern Turkestan. The Chengde gardens were carefully laid out to serve as an arena for the affairs and ceremonies of the multicultural empire of the Great Qing, to which China, both Inner and Outer Mongolias, and Tibet belonged. In Chengde the emperor commissioned the many paintings, albums and gazetteers that celebrated his own scholarly genius as well as the universality of his reign. The sophisticated culture of Tibetan and Mongol Buddhism was ostentatiously present in the Wai Ba Miao temples of Chengde. The steles of these religious gardens bore inscriptions in Tibetan, Mongol, Manchu and never Chinese only. One needs to be reminded of the ethnic character of the Qing court: the Manchu and Mongol clans were allied, and intermarriage with Chinese families was forbidden. The Qing emperor's first language was Manchu and he used Manchu as one of the two administrative languages of the empire. Issues of political power, subjectivity, and inside and outside boundaries cannot be considered in the light only of classical Chinese thought as one needs to include in the analysis of these imperial gardens of Inner Mongolia the application of Tibetan Buddhism and Manchu statehood to the concepts of embodiment, patronage and cosmology.

Before analyzing further the gardens of Chengde a few remarks about space and locale seem appropriate. The Chengde gardens are of two spatial kinds, the imperial gardens of the Bi Shu Shan Zhuang and the other gardens in the city and around the imperial residence. Culturally speaking, this dichotomy may not be relevant to the perception of the gardens at the time. The religious metaphors expressed in the Chengde gardens turned them into transcendent representations of the Empire, at least for the emperor's guests who were invited to contemplate his domains from the mountain kiosks of the Bi Shu Shan Zhuang. ${ }^{4}$ It would not be entirely appropriate to employ the Western concept of locale here, especially since the Chinese civilization has developed its own sense of place and articulated it around feng shui (geomancy) and feng tu (local conditions). Because a basic unity links all the various gardens, none of these places can escape the pervasive concept of feng $t u$, which defines the physical and human environment specific to a place. Through feng $t u$, common conceptual membership to a single place unifies the imperial gardens of Ru Yi Island, at the center of the lake district of the mountain manor, and the peasant fields, south of the $\mathrm{Pu}$ Le Temple and east of the Qing residence. Court and civil gardens belong to the same field of cultural vision as if physical boundaries did not exist between $\mathrm{Ru}$ Yi Island in the west and the Pu Le Temple in the east. The 36 vistas of the Yu zhi Bi Shu Shan Zhuang shi (literally Imperial Poems on the Bi Shu Shan Zhuang) altered the true perception of lakes, artificial hills, screens of trees, the residence and city walls, dikes, the Wulie river and terraces. ${ }^{5}$

I will focus on the maps and paintings of the Chengde gardens in terms of the relationship between place and spectacle. It seems legitimate to look at garden iconography as a primary source of official information on imperial geography in order to study the interaction between culture and movement through space. It is tempting to interpret the contradictions and silences of the visual documentation on Chengde as the implicit reflections of ontological explanations that were not acceptable as textual statements. Here lies the importance of cartographic analysis in the original cultural context, since maps and landscape paintings provide better supports than texts for the expression of what modern geographers would first think to be ambiguous and incomplete statements about place. Paintings and engravings are indeed quite apt at rendering notions such as disappearance. For lack of a better term, I shall mean by 'disappearance' the spatial movement of transition, distortion and elimination of geographical features (physical and cultural) which, in the paintings and maps of the Chengde gardens, has the effect of transporting the viewer to a different place of reference. There is, of course, a second type of disappearance, directly related to the ephemeral nature of gardens, and I briefly allude at the end of this paper to the timber structures of Jin Shan temple, when they fell apart and were restored.

The materials on the gardens of Chengde as depicted during the last part of the Qian Long Emperor's reign (1780-96) are in the Chengde Gazetteer and Album of Imperial Poems. Qian Long's interest in documenting the administrative extension of the province of Zhili (present-day Hebei province) 
beyond the Great Wall induced him, in 1756 , to command the composition of the local history of the Chengde prefecture. Qian Daxin and Jiyun completed the Chengde Gazetteer in $178 \mathrm{I}$. Both compilers accompanied the emperor to Chengde and Mulan to gather the materials they needed for their work. The gazetteer included not only a number of administrative maps of the prefecture and bird's-eye view illustrations of Chengde temples and Jehol hunting lodges, but also a simplified version of the Kang Xi Emperor's poems and vistas (figure 2). The woodblock engravings of the gazetteer are fascinating because they convey information on the representation of landscape ideal by the Kang Xi Emperor, his grandson the Qian Long Emperor and their guests at the summer capital. They complete and illustrate descriptions transmitted to us in several travelers' accounts as well as the vistas of the Album of Imperial Poems. Because these visual records can be examined for what they occlude, I have selected plates from the album and maps from the gazetteer and studied the intriguing theme of disappearance by comparing garden portraits in cartography and landscape painting. ${ }^{6}$

Scrolls of landscape paintings extend the cultural construction of garden landscapes. The original aspect of the Chengde gardens can be best seen today in two landscape paintings now in the map division of the Library of Congress: the Tai wan di $l i t u$ and the Rehe xing gong quan $t u$. The impress of Qian Long's authority on the Chengde landscape is visible in both paintings. By coincidence, both paintings were made $c .1780$, have the same scale and the same orientation toward the north-east. The accuracy of the architectural details is so remarkable that the painters' omissions have to be intentional. Examination of the paintings shows how the site of Chengde was divided into geographical sectors that formed four quadrants around the pivot of Jin Shan Mountain. This division into a court center, an urban south, a rural south-east, a religious north-east and a natural west was implemented from the very founding of the Qing summer capital in 1703. Spatial segregation between the land-use types is quite elaborate as can be seen in the oblique renditions of these two paintings of Chengde.

The title of one landscape painting is purely descriptive: Rehe xing gong quan tu ('Complete Map of the Hunting Lodge of Rehe'). The highly visible temple terraces may explain why the name Tai wan di li tu (literally Map of the Geography of the Bay of Terraces) was given to the other landscape painting of Chengde. Tai refers to the terraces of the Eight Outer Temples as well as the terraces of the fields cultivated on the eastern bank of

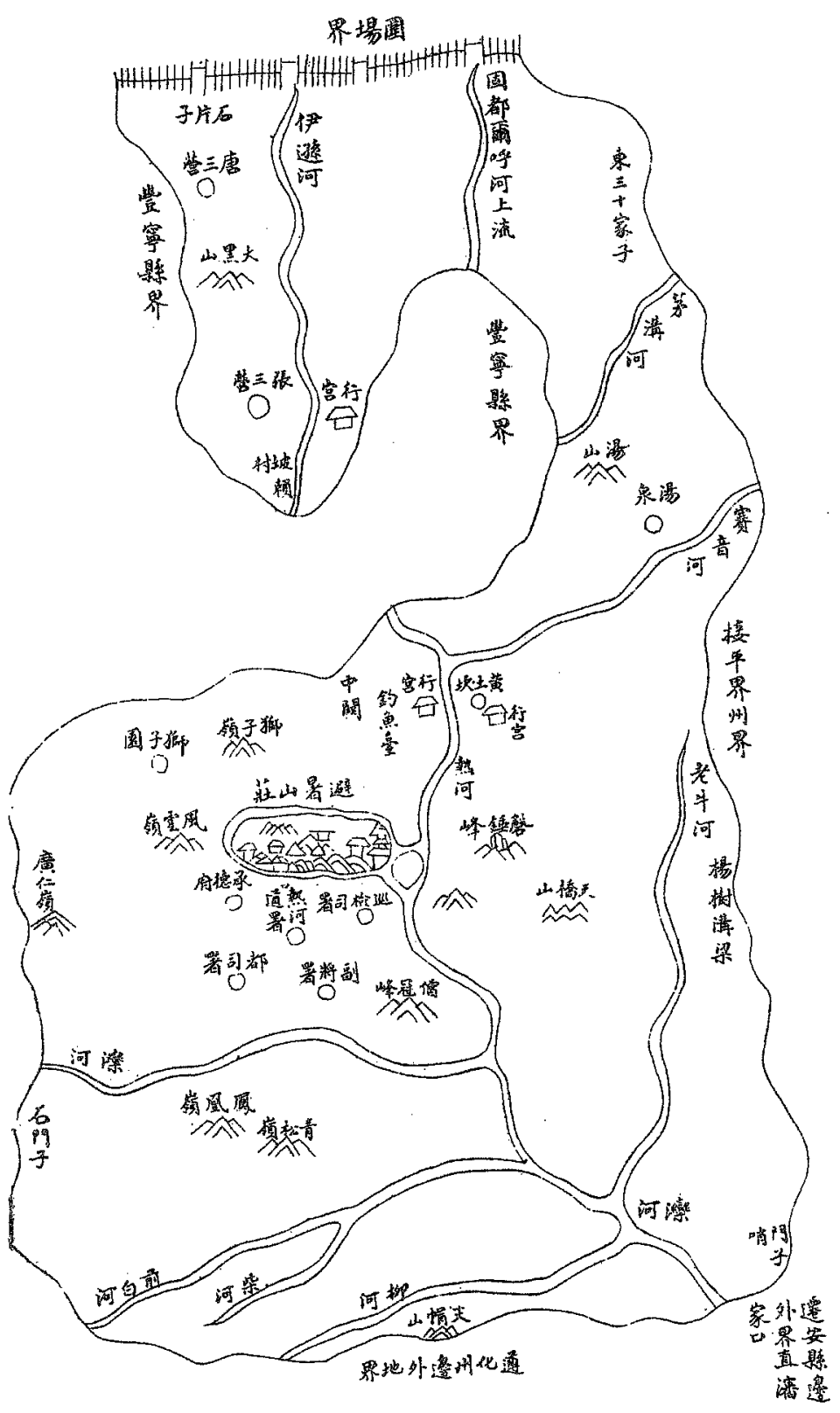

FIGURe 2. Chengde fu tu (Prefecture of Chengde); from Rehe zhi. 
STUDIES IN THE HISTORY OF GARDENS AND DESIGNED LANDSCAPES : FORET

the Wulie River. The gardens of the Bi Shu Shan Zhuang have their own terrace: Yue Tai (literally Moon Terrace), which is located at the western edge of Jin Shan Mountain. The title also invites the observer to compare the Bay of Terraces (in Chengde) with the Mountain of Five Terraces (Wu Tai Shan, a sacred mountain in Chinese and Central Asian Buddhism). Calling the basin of Chengde 'Bay of Terraces' reinforces the fusion of the religious and secular elements that participated in the landscape spectacle that the emperors enjoyed seeing around the Bi Shu Shan Zhuang. The alignment of $\mathrm{Pu} \mathrm{Le} \mathrm{Si}$ (literally Universal Joy Temple) and the pillar of Chui Feng (literally Chime Stone Peak) was the cause première of the building of the temple mandala, and appropriately enough this axis is overemphasized in the landscape paintings of the Bi Shu Shan Zhuang. In the Tai wan di li tu both the pagoda of the Yong You Temple and the artificial mountain of Jin Shan Temple stand out in the lake district of the Bi Shu Shan Zhuang. In the Rehe xing gong quan tu, however, the pagoda of Jin Shan has been erased from the summit of Jin Shan Mountain. ${ }^{7}$ Its disappearance will be discussed below.

The representations of the gardens in the two landscape painting confirm the importance of a classification scheme based on spatial locations. Both painters emphasized the massive wall that separates the court gardens from the urban and religious gardens. Inside and outside the walls of the imperial residence, the Tai wan di $l i t u$ and the Rehe xing gong quan tu describe temple gardens, orchards and vegetable gardens, scholars' gardens and urban gardens. Court gardens are distinguished from mundane and religious gardens only in that, whatever their functions, they are located behind the massive walls of the Bi Shu Shan Zhuang, and therefore belong to the emperor's private domain. City gardens occupy limited space at the southern bottom of the Tai wan di li tu and Rehe xing gong quan $t u$. Such gardens figure more prominently in the Rehe xing gong quan tu because this painting represents only the public buildings of Chengde: temples, court offices and barracks. Trees and hills fill the space where in fact the low houses of the capital of the prefecture stood. The city had no public park, and its private gardens were half-hidden in the enclosed back courtyards of the most important houses. Tree tops above their walls suggest that these gardens were apparently similar in architecture to gardens south of the Great Wall because showing tree tops above walls is a familiar way by which Jiangnan gardens have been depicted.
An interesting discrepancy in the pictorial treatment of the wall that encloses the Bi Shu Shan Zhuang may require an explanation: the Album of Imperial Poems erases the wall from the vistas while the landscape paintings enlarge the size of the same wall. As for the maps of the Chengde Gazettecr, they. show the wall but often blank space replaces the gardens and buildings of the mountain manor (figure 3 ). A first explanation would come to mind: no one in the Qing audience except the emperor himself would have been aware of this discrepancy about the nature of Chengde's walls, since access to visual information on Chengde was guarded by Qian Long. Comparison between different representations of Chengde was difficult as paintings, vistas and maps were originally kept in palaces, in Beijing and Chengde, that were physically apart. This would prevent the perception of a contradiction about wall presence: if Chengde is the modest mountain manor of a Confucian ruler, no wall would be needed, but if Chengde is the lavish summer capital of the Great Qing, visitors from Central Asia would expect a massive wall. A second explanation would be related to the physical position of the observer and the depiction of the actual terrain. In the album plates the residence wall

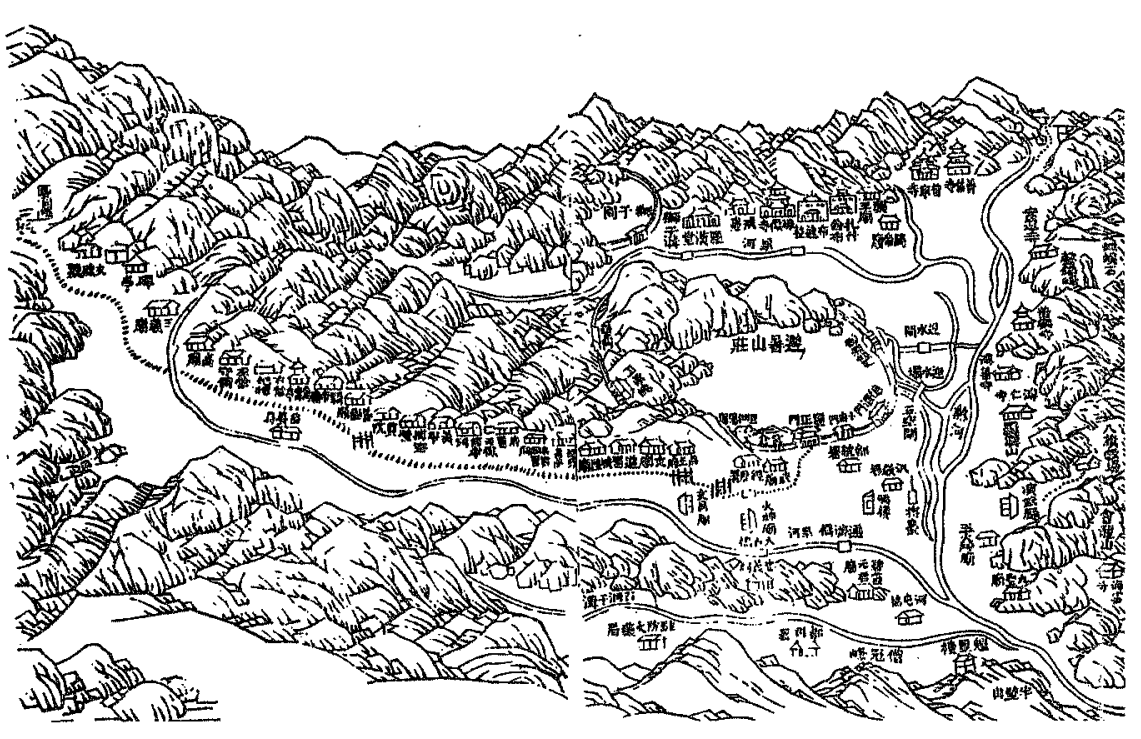

FIGURE 3. City of Chengde; from Rehe zhi. 
is not visible, so that the Bi Shu Shan Zhuang gardens seem to extend into the distance without limit. The inner gardens of the Bi Su Shan Zhuang are shown in the oblique perspectives of landscape paintings, and the gaze of the observer is first stopped by the impressive red gate of the residence, and this is an effect that the artists sought to achieve (figures $I$ and 4 ). In reality, if the observer is standing on the hills and terraces east of the residence, his or her view of the Bi Shu Shan Zhuang gardens is not blocked by the wall.

Within the visual account of the gardens that the emperor offered as present, the residence wall of the Bi Shu Shan Zhuang is never visible: the vistas of the Album of Imperial Poems on the Bi Shu Shan Zhuang depict court gardens without the wall that encircled the residence. Further, the court gardens are themselves imitations of Chinese literati's gardens and in

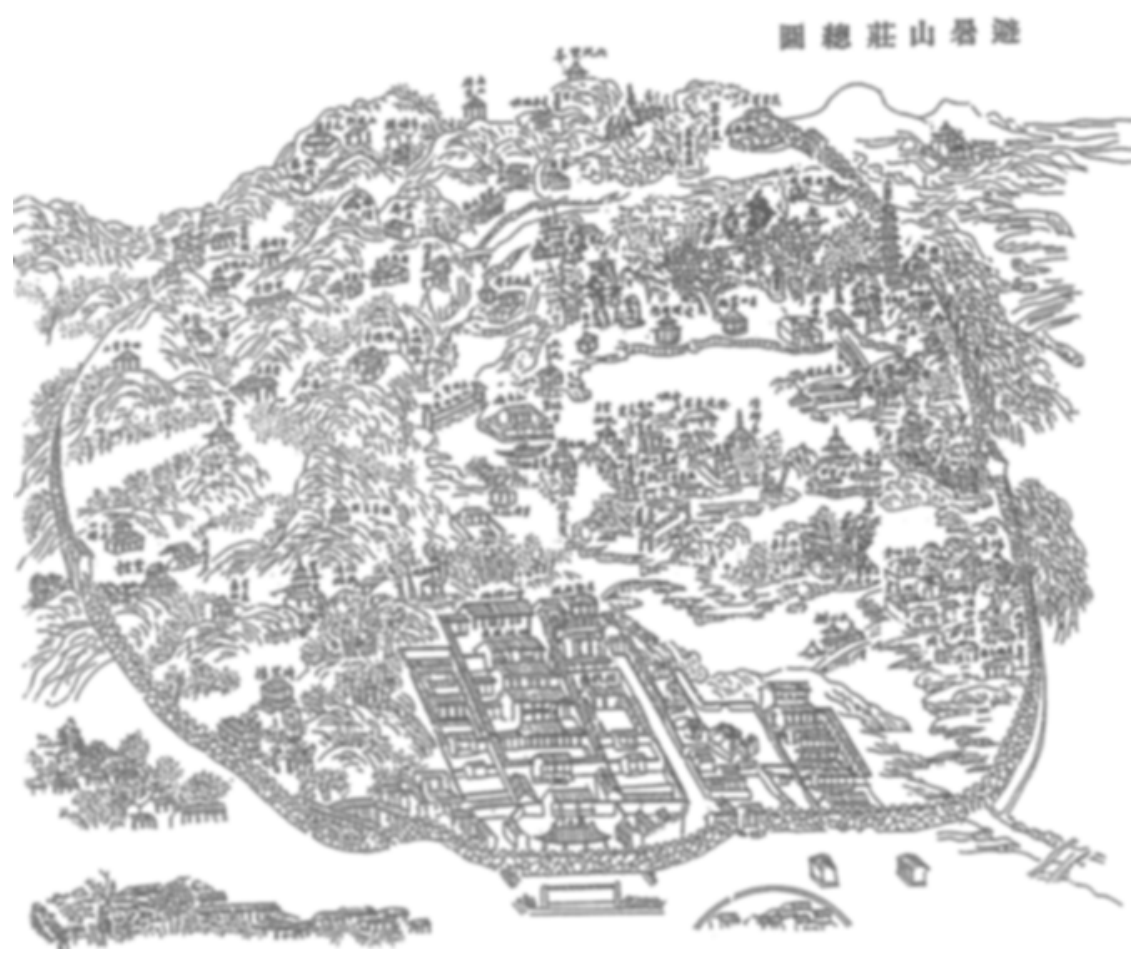

Frgure 4. Bi Shu Shan Zhuang zong tu (Comprehensive Map of the Hill Station of Chengde); from Rehe zhi. this respect are not different from the gardens that the Manchu emperors built near Beijing, south of the Great Wall. Because the inside gardens were replicas of the outside gardens, the internal duplication of elements found outside the mountain manor constituted a rhetorical method that implied the negation of the physical barrier that separated the outside and inside of the Bi Shu Shan Zhuang. As a consequence, these gardens negated the objective reality of the outside world, since they ignored the boundary between what is inside and what is outside, as if the world consisted of a vast garden of gardens. In his gardens the emperor was everywhere and let it be believed that he was similarly everywhere in the Empire. This ubiquity is important in a political culture that merges the functions of emperor and seat of power. The metaphorical effect of ubiquity is achieved through the disappearance of the residence walls in the representation of the garden vistas and through the architectural suggestion that the Great Wall of China did not interrupt the extension of Chinese garden architecture from southem China to Inner Mongolia. One sees here an example of conflation of Buddhist negation of reality (atman) and the affirmation of political desire, rather than a case for philosophical divorce between inner and outer realities.

\section{Gardens and domination}

As part of the Qing dynastic enterprise, garden construction in the Bi Shu Shan Zhuang was an architectural undertaking replete with political symbols. The Qian Long Emperor organized gardens following the same policy of union and division he had implemented in the territorial organization of Manchu conquests in Central Asia. The emperor used the pictorial tools of scale change, orientation and alignment to shape the perception of his gardens. These gardens had direct implications for the understanding of the layered geography of the Qing Empire since they were represented to bring out the supremacy of imperial power. Poems, paintings, maps and visits of Chengde today have provided evidence on the organization of the cultural landscape and have shown that well-defined areas of the Chengde gardens were conceived as a rendition of the pleasure gardens of southern China or the religious architecture of Tibet. The presentation of the Bi Shu Shan Zhuang vistas modified the physical configuration of the site of Chengde to create a new cultural geography of the place by transforming the perception 
of natural topography, and adding and removing superstructures such as the Jin Shan Temple. Landscape paintings and album vistas have preserved the eighteenth-century appearance of the villa gardens built within the mountain district, but assist in the subjective perception of the mountain manor by aggrandizing the size of the informal gardens of the lake district, north of the palaces. If one trusts the plans of the Chengde Gazetteer, the gardens of the villas of the mountain district of the residence were similar to the now-extinct gardens of the hunting lodges where every summer the court rested on its journey between the capital city of Beijing and the wilderness of Mulan.

The paramount concern for domination of the physical and metaphysical realms can be seen in garden landforms, locations, orientation, and place names The 'As-You-Wish Scepter' (Ru Yi Zhou) and the 'Golden Mountain' (Jin. Shan) islands, the 'Nine Mountains and Eight Seas' (Jiu Shan Ba Hai) are blatant symbols of emperorship. Domination of the landscape was also achieved through movement into two spaces of disappearance: the progression, visual focus and extension of the scenery vistas at the scale of the mountain manor, and at the scale of the prefecture of Chengde the circuit that led the emperor and his hunting expeditions from culture to wilderness through the network of hunting lodges and temporary camps. Scale was to be dominated too, and through the manipulation of visual effects and literary metaphors the Qian Long Emperor suggested to his audience the reduction of the empire to the gardens, and the expansion of the gardens to the cosmos (figure 5).

At the same time the emperor drew strict functional boundaries within the gardens. The gardens of the Confucianist palaces and the informa and religious gardens of the lake district had to be kept separate since the conduct of public affairs was distinct from relaxation, poetic and painting activities. The park of Wan Shu Yuan was reserved for diplomatic receptions and festivities. Moreover the mountain manor walls efficiently cut the gardens of Chengde into two domains, a court and a commoners' domain. The swift and public punishment of trespassers by Qian Long's guards reinforced the height perception of the residence walls and ensured the inviolability of the garden boundaries. As a Korean envoy to Chengde noted:

One morning I passed by the Kuang-pi ssu-piao p'ai-lou where thousands of people had gathered. The marketplace was crowded and heaven and earth resounded with boisterous laughter. Suddenly I saw a man beaten to death and lying in the street. I folded my fan, hastened my pace and wanted to pass by when one of our servants rushed up to me and shouted: 'There is something strange to be seen!' I asked him from a distance: 'What's the matter?' He said: 'Somebody stole peaches from the palace. He was beaten by the guards, he collapsed and fell to the ground.' I vented my disgust, ill-at-ease and without any further look I went away. ${ }^{8}$

The Kang Xi Emperor planned the construction of formal Confucianist gardens within the palace complexes at the extreme south of the Bi Shu Shan Zhuang, and informal leisure gardens in the lake district north of the palace district. A natural environment of prairie and forest occupies the area north of the lake archipelago. The secluded gardens of the mountain district sit on the gentle hill of the Bi Shu Shan Zhuang, west of the lake district. Most of the mountain manor actually consists of a large rounded hill covered with evergreen trees, its summits topped by pavilions and its ravines concealing rest houses. The mountain manor gardens stood at the center of the Chengde complex. South of the Bi Shu Shan Zhuang were the equally walled gardens of Chengde's urban compounds. Monks strolled through religious gardens in the north and east of the residence; farmers tended their fields on a terrace in the south-east of the residence.

Judging from their geographical positions in the Tai wan di li $t u$, the Chengde gardens can be grouped into three functional categories: (I) commoners' gardens in the city itself, and peasants' gardens behind the first ring of Chengde mountains. The tenders of these gardens would have been Chinese settlers and Manchu bannermen; (2) court gardens built inside the Bi Shu Shan Zhuang, with further subdivision into palace courtyard gardens, archipelago gardens, and mountain villa gardens. These gardens would be Chinese, with the exception of the Wan Shu Yuan garden, which only Mongols and Manchus would have found to be attractive because forests and prairies would be better appreciated by cultures with a pastoral tradition; and (3) religious gardens inside and outside the Bi Shu Shan Zhuang, each enclosed by the outer walls of a temple. The gardens and gardeners of the Wai Ba Miao temples would have had Tibeto-Mongol origins, just like the monks of the Yellow Church who worshipped in these temples.

These gardens can be subdivided into urban ornamental gardens and peasants' fields, orchards and vegetable gardens. The gardens of the Bi Shu Shan Zhuang are functionally heterogeneous, unlike the homogeneous 
THE IMPERIAL GARDENS OF CHENGDE

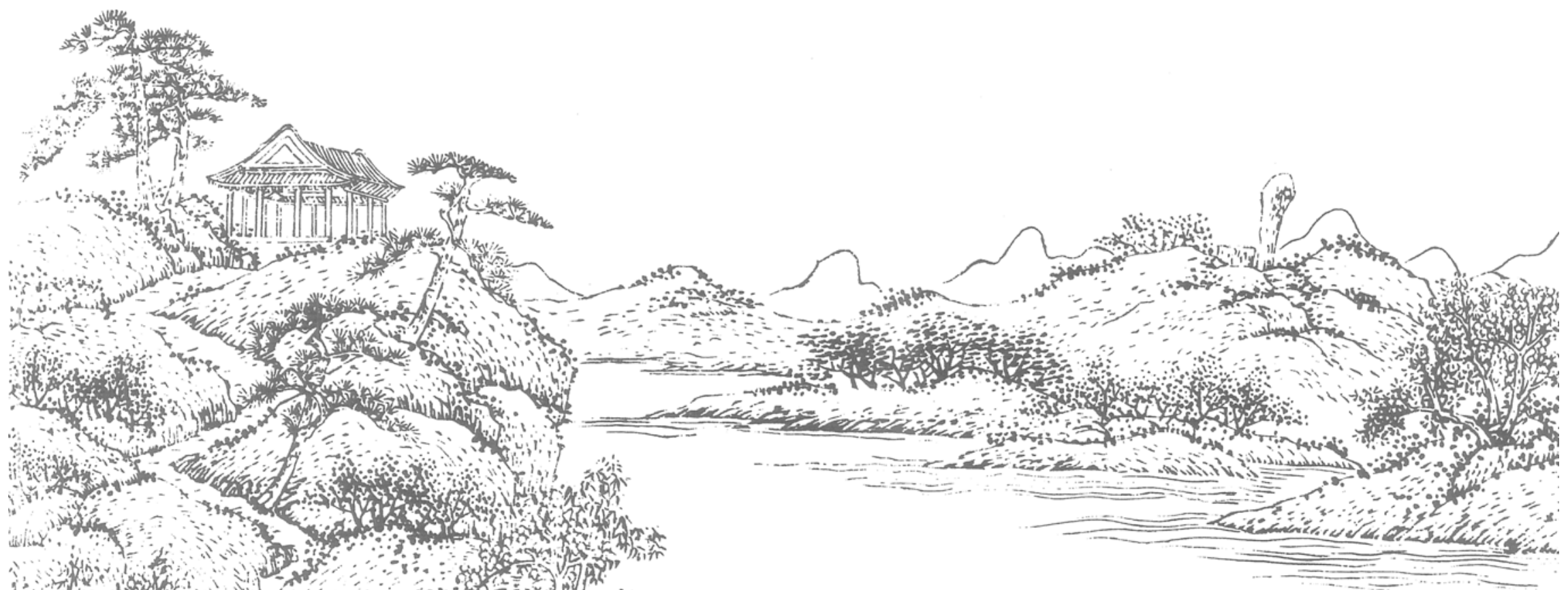

FIGURE 5. Chui Feng Luo Zhao, Garden Vista I2; from Yu zhi Bi Shu Shan Zhuang shi. 
STUDIES IN THE HISTORY OF GARDENS AND DESIGNED LANDSCAPES : FORET

gardens of Chengde proper. Closer examination of the mountain manor gardens indeed reveals that the $\mathrm{Bi}$ Shu Shan Zhuang possessed gardens of the two other categories inside its enclosure, religious gardens and mundane gardens. The Manchu emperors' gardens of the lake district of the Bi Shu Shan Zhuang may be considered imitations of the private garden architecture cultivated by the Chinese gentry of Jiangnan. The wealthy salt merchants, bankers and officials of Yangzhou, Changzhou and Suzhou indulged themselves in prestigious ways by patronizing art and book connoisseurs in their gardens. The gardens designed by the Qian Long Emperor and the urban gardens designed by officials and merchants in Chengde and along the Great Canal were, therefore, similar in inspiration. The main differences between imperial and private gardens were found not in design or ideals but in scale and means of representation; and of course in political purposes: retirement from public affairs in the case of the private gardens of Jiangnan as opposed to submission through seduction in the case of the imperial gardens of Inner Mongolia.

What does the perception of spatial organization in the Bi Shu Shan Zhuang reveal about the complexity of the domination landscape in the Qing summer capital? The meaning expressed by the gardens of Chengde changed according to political and religious circumstances. The new procedure for election of the Dalai and Panchen Lamas, the creation in Turkestan of Xinjiang (literally New Frontier), the return to the Qing Empire of the Torghut Mongols, the emperor's identification with Manjusri, the Bodhisattva of wisdom, were significant decisions that were celebrated by the foundation of new temples. Although he stated the exact opposite, Qian Long as a garden patron wanted to emulate his grandfather, the Kang Xi Emperor. He also wanted to please the Tibetan state preceptor, who had initiated him into Buddhism, while reaffirming the supremacy of his rule over the Tibetan church in the stelas erected in the Yong He Gong temple of Beijing. Qian Long was very aware of the importance of the historical precedents set by the emperors and scholars of previous dynasties (Yuan and Ming, especially), and he provided the funds needed for the restoration of the ruined temples of the Jin and Liao dynasties in the north China frontier. He nevertheless sought inspiration in contemporary models (the temples and garden cities of Jiangnan and Lhasa) and traditional virtues (the frugal environment and martial character of the Manchu bannermen).

\section{Topography of the gardens}

The Qian Long Emperor chose to spend almost all his summers in a mountain manor at the center of a long green valley that runs from north to south. The mountains that surround the mountain manor appear to be steep but a rounded low hill occupies the center of the basin, on the western shore of the Wulie river. The symmetrical palace complex of the Bi Shu Shan Zhuang was built in the plain that lies between this hill in the west and the Wulie river in the east. Groves of trees were planted around the pavilions, halls and temples of the residence. The city of Chengde developed south of the imperial residence hill while fields were cultivated on the eastern terraces that flank the Wulie river. The lake district of the $\mathrm{Bi} \mathrm{Su}$ Shan Zhuang contains a total of eight lakes that isolate an archipelago of nine islands covered with man-made mountains. These man-made islands were placed between the palace district in the south and the prairie district in the north, the mountain district in the west and Rehe spring in the east. The Wulie river runs parallel to the eastern wall of the residence.

Only visible from Jin Shan temple or from the mountain kiosks of the Bi Shu Shan Zhuang, this disposition nevertheless is reminiscent of the geomantic Taoist and Buddhist paradigms. The geomantic qualities of the gardens of Chengde were emphasized in the construction programs. Temples were located to channel cosmic energy entering the Wulie valley from the inauspicious north-east direction. 9 The introduction of yin elements through the filling of the Saihu lakes and planting of the Wan Shu Yuan forest north of the lakes was meant to correct the strong yang character of the Bi Shu Shan Zhuang mountains, especially in the east, where Chui Feng Peak stands erect. The introduction of these male and female features to the natural landscape of Chengde is not sufficient proof to conclude that the Qing summer capital was built according to geomantic principles since geomancy alone was indeed not at the origin of garden design. When he positioned artificial mountains and lakes in the Chengde site, Kang Xi nevertheless proposed a geomantic reading of the built landscape of the mountain manor. By building more religious structures and reordering the constructed landscape as recorded in the paintings of Chengde, Qian Long enhanced the geomantic qualities of the landscape of the site. The administrative maps of the Chengde Gazetteer depict the flow of the Rehe river as redirected in the geomanticaly auspicious direction. The river no longer flows from inside the mountain 
tnanor but remains outside the Bi Shu Shan Zhuang and parallel to the southern wall of the residence. Instead of the actual southward direction the Rehe river has an eastward course. What one sees therefore, is a series of steps in which geomantic awareness precedes garden construction, which is followed by a topomantic reinterpretation that poems, paintings and maps later legitimize.

The Taoist interpretation of the garden layout would be based on a system of analogies applied to local topography. The significance of the figure 'nine' for the nine islands of the mountain manor is related to the numerologica meaning of the character, 'to reunite.' Nine is moreover the emperor's ritual number, regardless of the actual sum of imperial items. In his explanation of the title jiu bian (literally Nine Arguments), Wang Yi, a famous librarian at the Han court, wrote that bian (literally to change), refers to elucidating the virtue of Tao in order to persuade the emperor to change. He added that jiu (literally nine), a Yang number, forms the fundamental principle of the Tao Heaven has nine stars to regulate the North Star; Earth has nine regions in order to establish the empire. The jiu zhou are the nine provinces whose total forms the empire of China. Qian Long's residences of both the Yuan Ming Yuan and the Bi Shu Shan Zhuang have archipelagos of jiu zhow where the nine provinces are represented as nine islands. Nine also assumes a qualitative value linked to the system of yin-yang polarity. The emperor has a yang function when he exercises his power and a yin function when he listens to his ministers' advice. Finally, nine refers to cosmic change and regulation. ${ }^{10}$

The Buddhist cosmic archetype is called Jiu Shan Ba Hai (literally Nine Mountains and Eight Seas). It corresponds to nine concentric mountain ranges that are separated by eight seas, together forming the universe. The central mountain of the nine ranges is Sumeru (also called Kunlun or Kailas), which is the central mountain of every world. Around it are eight circles of mountains and between them the eight seas. ${ }^{\text {II }}$ The concentric ranges around Sumeru are called Qi Jin Shan, or the 'Seven Golden Mountains.' ${ }^{\text {I2 }}$ The existence of a central mountain inside the Bi Shu Shan Zhuang would confirm that the symbolic composition of 'Nine Mountains and Eight Seas' served as the major theme for the design of the lake district.

Jin Shan Mountain is the best candidate for a metaphorical identification with Sumeru because it is the highest summit of the garden hills. ${ }^{13}$ Located on the eastern side of the Chenghu lake, Jin Shan has since its completion in
1708 acted as the pivot of the Chengde gardens. In the opening sentences of the preface to the Album of Imperial Poems, the Kang Xi Emperor emphasized the geomantic location of Jin Shan Mountain. ${ }^{14}$ Functioning as a microSumeru mountain, Jin Shan formed in Chengde the pivot of the world, a column through which micro-cosmos and macro-cosmos communicated. The incorporation of court gardens and gardens belonging to the urban and religious quadrants of Chengde into the geographical center of the Bi Shu Shan Zhuang added force to the Manchu claim of having included in the Bi Shu Shan Zhuang a model of the Sumeru mountain that would be Jin Shan Mountain (figures 6 and 7). The identification of Jin Shan and Sumeru is consistent with the placement of several landforms and structures discussed below.

\section{The Mountains, islands and temples of Jin Shan}

The effect of naming places is to create associations that can be historical, religious, architectural and geographical in nature. The name of Jin Shan has rich connotations in all these registers because it is the name of various mountains, islands and temples. This choice makes clear that the Kang Xi Emperor wanted to enrich the Jin Shan pagoda of the Bi Shu Shan Zhuang with a large number of references located in diverse parts of his empire. ${ }^{\text {Is }}$ The Jin Shan temple of the city of Zhenjiang (in Jiangsu province), has provided the model used for the construction of Jin Shan in Chengde (figure 8). Unlike the original model, a Buddhist pagoda, the Chengde Jin Shan, is crowned with a temple in which the supreme deities of Daoism are enshrined. The pagoda of Shang Di Lou (literally Supreme Emperor Pagoda), Chengde's replica of the Cishou pagoda of Zhenjiang's Jin Shan, is lower than its design model, having only three floors instead of seven. From their temple buildings, the Jin Shan islands offered the Kang Xi and Qian Long Emperors an all-embracing view of the landscape of the Yangzi river in Zhenjiang and of the Saihu lake in Chengde. Both islands in Chengde and in Zhenjiang have had hot springs in their immediate vicinities. The rockeries of the Jin Shan islands concealed legendary caves in order to underline the direct filiation between Chengde and Zhenjiang temples, as if the emperors were willing to demonstrate their abilities to erase the distance that separates Jiangnan from Inner Mongolia. 
STUDIES IN THE HISTORY OF GARDENS AND DESIGNED LANDSCAPES : FORET
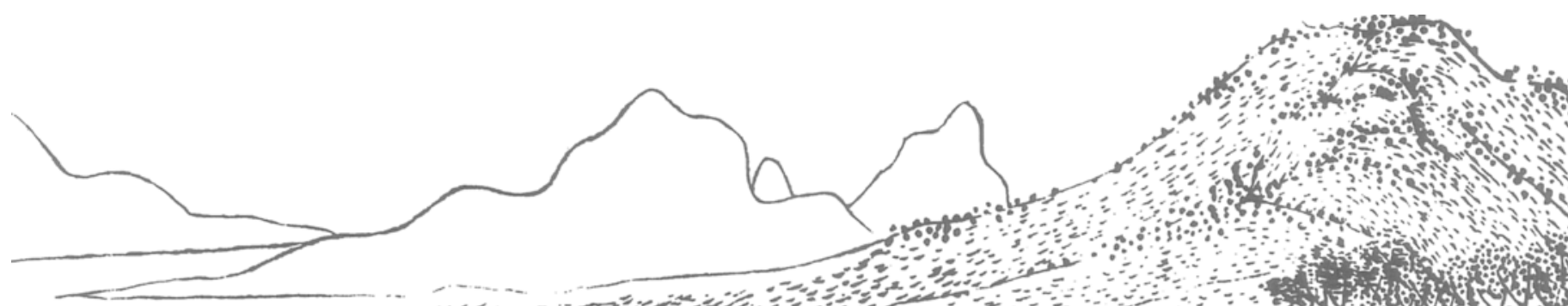
1

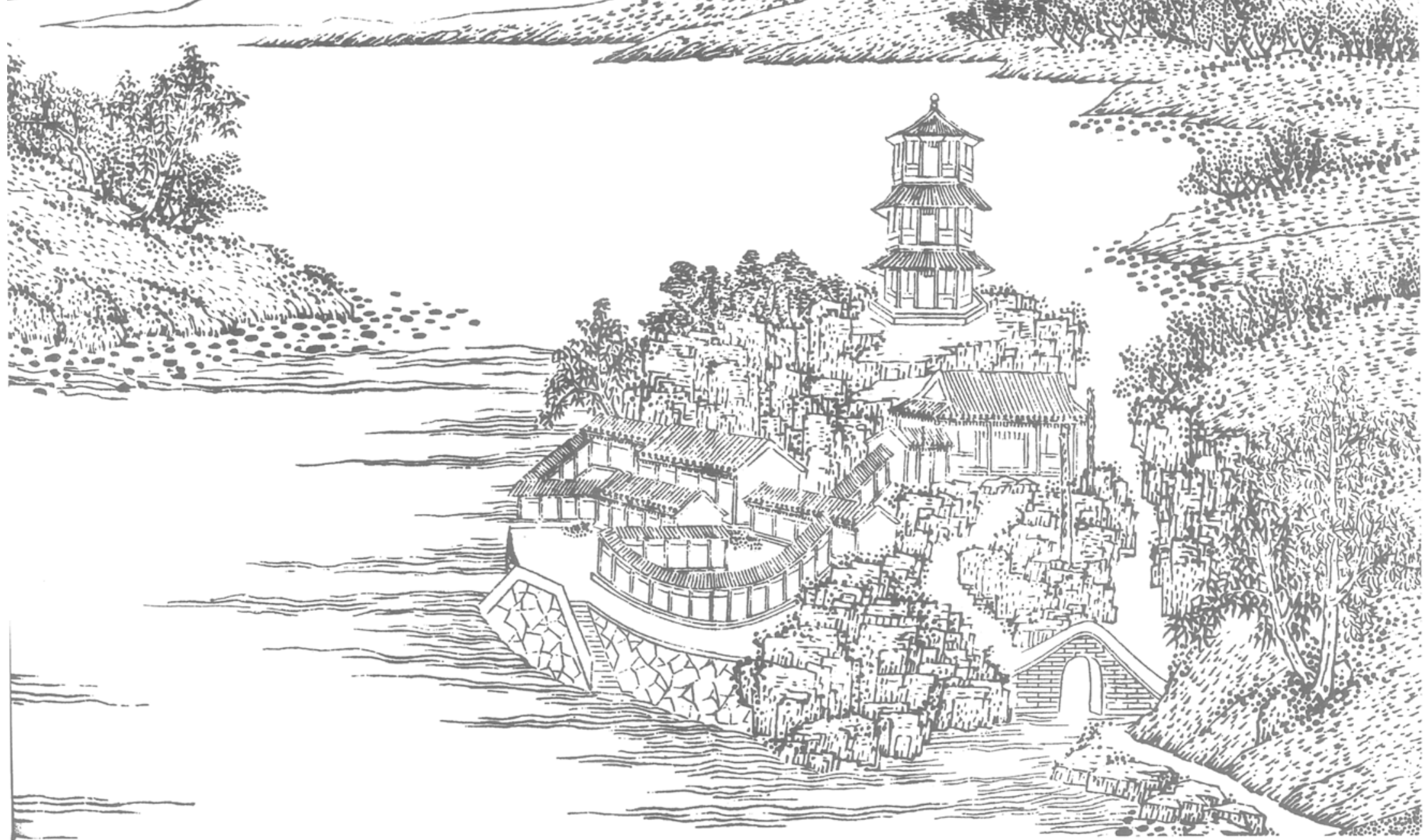

fIgure 6. Tian Yu Xian Cheng, Garden Vista I8; from Yu zhi Bi Shu Shan Zhuang shi 


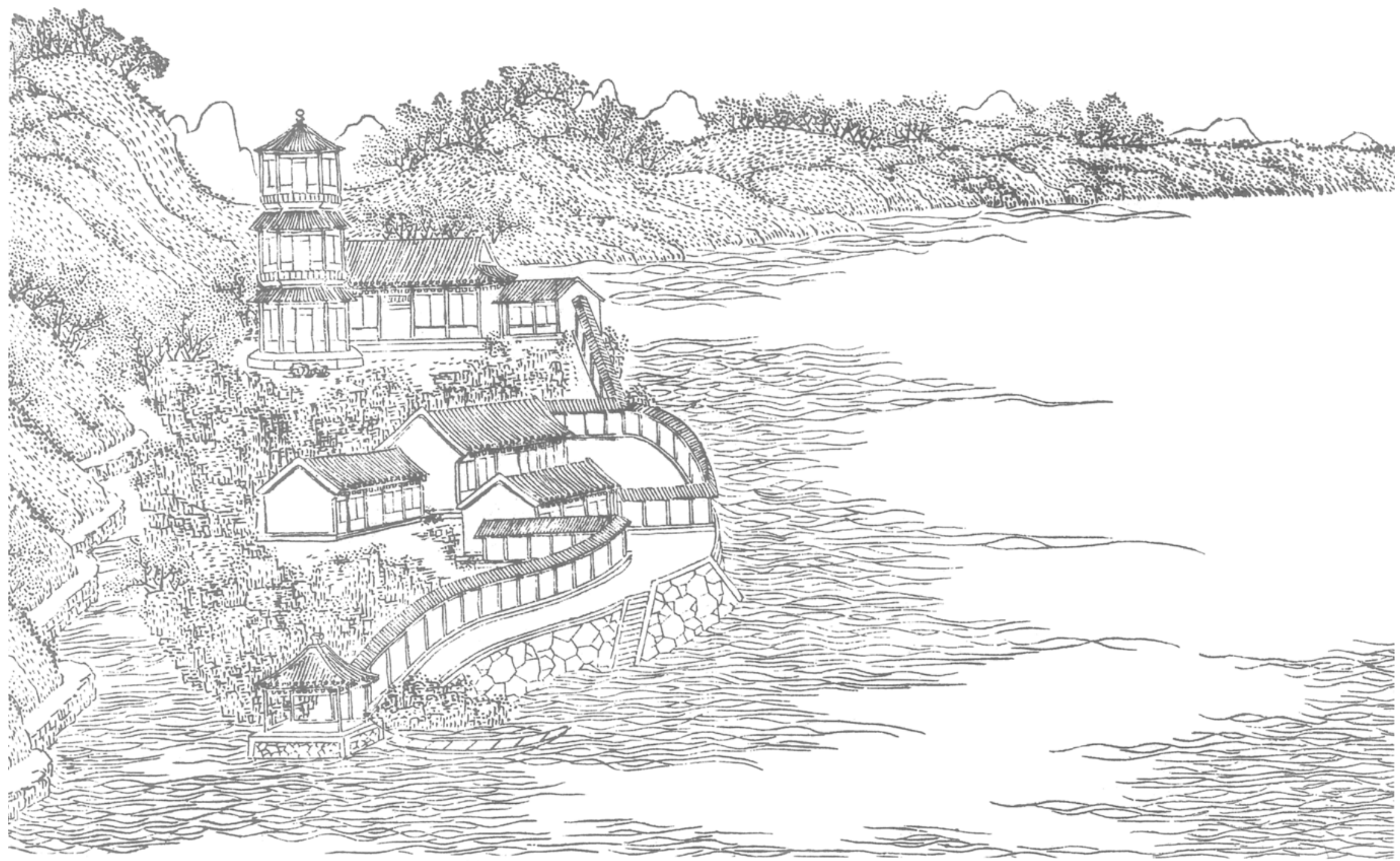

FIGURe 7. Jing Shui Yun Cen, Garden Vista 32; from Yu zhi Bi Shu Shan Zhuang shi.

The Kang Xi Emperor's Jin Shan Mountain proclaimed the universality of the ecumenical Qing Empire in an elaborate way. In the Tian Yu Xian Cheng vista Kang $\mathrm{Xi}$ had represented the superstructures built on and around the summit of the artificial island of Jin Shan. The plate depicting this vista shows how the island with its pagoda served as a spatial support for disappearance. Access to the Jin Shan Mountain was either by boat from Ru 


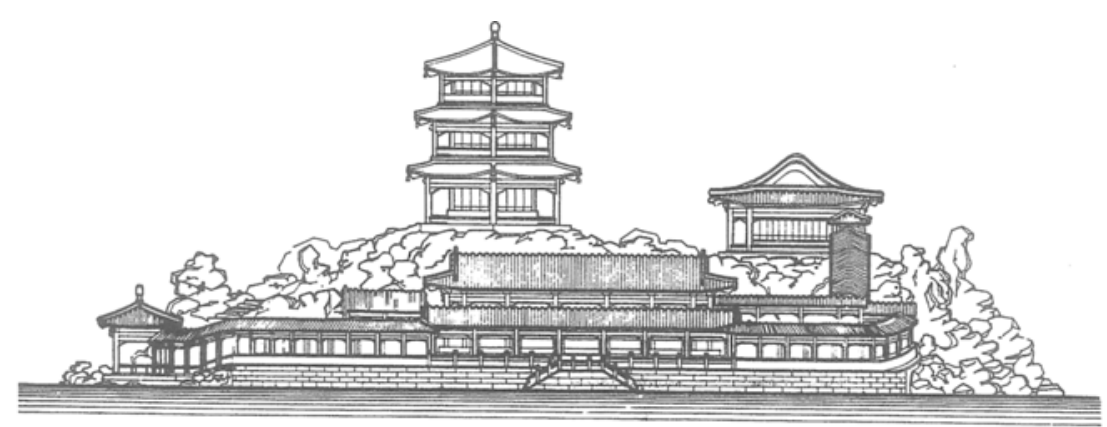

金山正立面

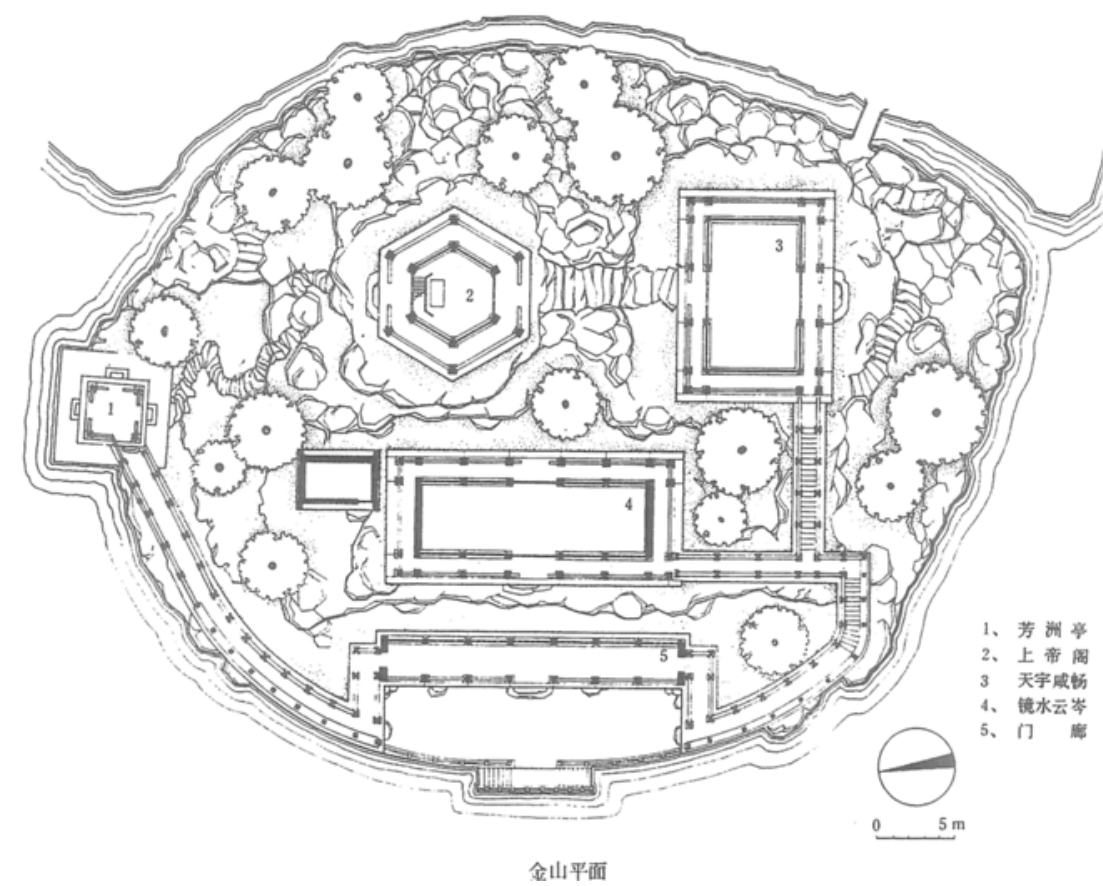

FIGURE 8. Architecture of Restored Jin Shan; from Chengde gu jianzhu, p. I24.

Yi Island to a large rounded embankment, or from the continent along a narrow path that winds around rockeries. Might the first of these means of access symbolize the emperor's inspection tours along the Grand Canal to Jiangnan - the Chinese core where a Jin Shan temple is located - and the second one, expeditions into the Changbai mountains - the Manchu hearth were a Jin Shan mountain is located? On entering and leaving the Bi Shu Shan Zhuang, the emperor ascended to the Shang Di Lou, the pagoda on top of the Jin Shan mountain to offer sacrifices to Heaven. Two supreme Daoist deities were enshrined in the pagoda: the Dayu and Zhenwu emperors. The two structures at the summit of Jin Shan are the hall calle $\mathrm{I}$ Tian Yu Xian Cheng and the pagoda of Shang Di Lou of Shang Di Ge, which is also known as Jin Shan Ting (literally Golden Mountain Pavilion;. The same temple building is called lou, ge and ting, and is a storied pagoda with an octagonal architecture. The Jin Shan temple may be associated with the Sumeru sacred mountain since constructions on the top of Sumeru are traditionally supposed to be round. ${ }^{16}$

The comparative significance of the mountain and temple may be debatable since details of the landscape paintings of the Bi Shu Shan Zhuang disagree with each other. Jin Shan Mountain disappears under the accumulation of religious superstructures in the Tai wan di li tu map, whereas the mountain does not have a single building on it in the Rehe xing gong quan tu map (figures 9 and Io). This would imply that the representation of the mountain is more significant than the representation of the temple. Kang Xj maybe suggested a resemblance to the Jiu shan ba hai landscape archetype, thus ensuring that the Jin Shan metaphor as a cosmic pillar would never be more than a metaphor. It may also mean that Jin Shan was primarily designed to serve as a place for the union of Chinese-inspired garden vistas and the north China frontier landscape, of place names and poems in Chinese and Manchu, a Taoist temple built on a Buddhist mountain, and a island of Jiangnan with a Manchurian peak.

The alignment of the Jin Shan Mountain with Chui Feng Peak, east of the mountain manor, has already been noted. Jin Shan was erected to form the highest mountain inside the gardens of the Bi Shu Shan Zhuang just as Chui Feng Peak was the highest summit of the Chengde basin. Jin Shan Mountain and Chui Feng Peak formed the poles of an axis that the Kang Xi Emperor conceived as early as 1708 . The Jin Shan pagoda has been described as one of the most beautiful vantage points of the mountain manor. From 


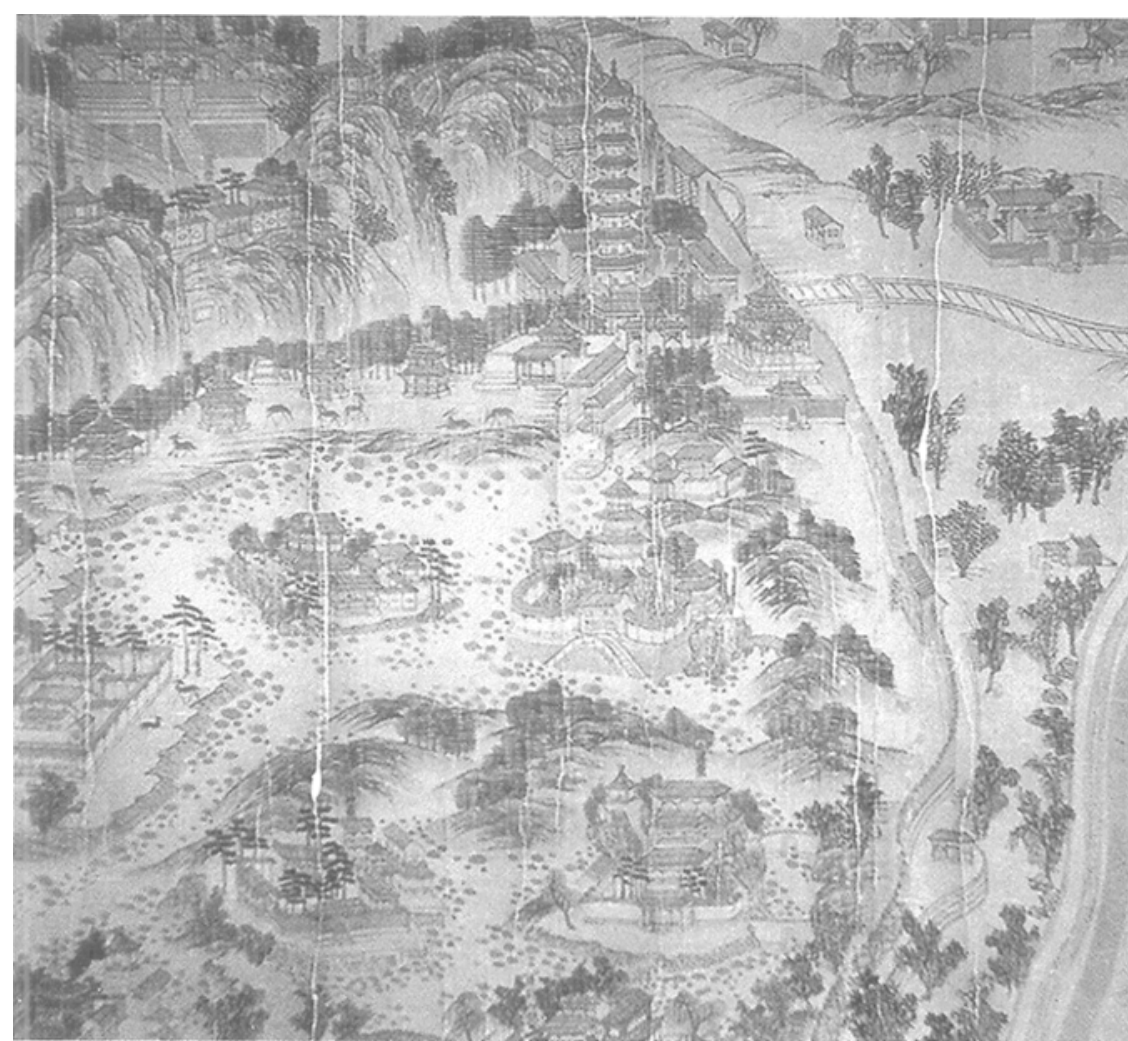

FIGURE 9. Jin Shan Mountain With its Temple; from Tai wan di li tu (detail). Courtesy. Library of Congress.

the pagoda, broad views reveal the layout of the residence garden district and the isolation of Jin Shan by lakes. ${ }^{17}$ Several important features of Jin Shan Mountain need discussion based on two plates that represent the Jin Shan vistas conceived by Kang Xi and popularized by Qian Long. The vistas of plates 18 and 32 in the Album of Imperial Poems (figures 6 and 7), illustrate two poems: 'Tian yu xian cheng' (Free Sky and Cosmos) and 'Jing shui yun cen' (Smooth Lakes and High Hills). The connection between Jin Shan Mountain and Chui Feng Peak is not made explicit in the illustrations of the Album of Imperial Poems because the island is not depicted when the

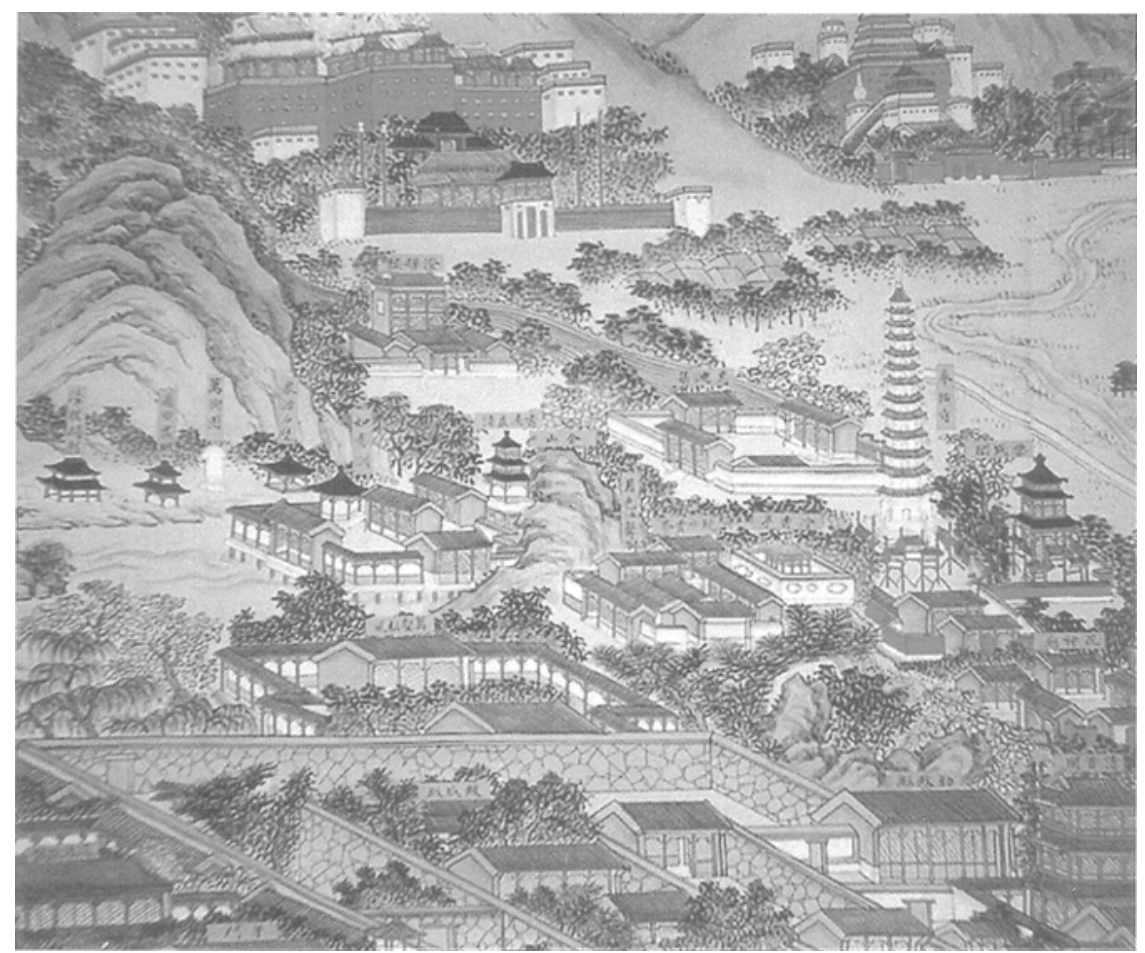

FIGURE IO. Jin Shan Mountain Without its Temple; from Rehe xing gong quan tu (detail). Courtesy: Library of Congress.

peak appears in plate I2, Chui Feng Luo Zhao (literally Sunset Glow at Chime Stone Peak). Six decades after the erection of Jin Shan the Qian Long Emperor decided to emphasize the crucial significance of the mountain-peak axis when he ordered the construction of the mandala terraces of the Pu Le Temple. In his dedicatory inscription to Pu Le Temple, Qian Long stated that this temple was exactly aligned with Chui Feng Peak to form an axis. ${ }^{18}$ Between the peak and the temple, Qian Long's axis merged with Kang Xi's axis, which continued westward to Jin Shan Mountain and $\mathrm{Ru}$ Yi Island. An alignment from east to west would connect the following points: the foot of Chui Feng Peak - the mandala of Pu Le Temple - the Yue Tai or Moon Terrace of Jin Shan pagoda - the Xi Ling 
Chen Xia (lit. Early Dew of Western Mountain) pavilion on Ru Yi Island. This alignment suggests a connection between the scepter-shaped island of $\mathrm{Ru} \mathrm{Yi}$ and the Sumeru Mountain.

A second feature of note is the location of $\mathrm{Ru} \mathrm{Yi}$ Island on the opposite side of Jin Shan Mountain, across Chenghu lake. Figure 6 shows how Ru Yi Island faces the half-moon terrace of Jin Shan Mountain. The crescent of the Moon Terrace (Yue Tai) has a Buddhist meaning that predicts domination of China and Mongolia. The political meaning of the moon metaphor is revealed in one of the Buddha's predictions: the Buddha told Yueguang'er that he would be reincarnated as a king when all China and Mongolia were converted to Buddhism. This optimistic prediction was the consequence of Yueguang'er's pleading for the Buddha's protection from his heretic father's persecutions. ${ }^{19}$ Figure 7 shows a boat at the northern end of that terrace, suggesting that a crossing took place from $\mathrm{Ru}$ Yi to Jin Shan, from the island in the west to the mountain in the east. The significance of the Jin Shan-Ru Yi couple derives partly from the political meaning, implied in the shape and name of the island, of Ru Yi as the monarch's scepter.

A third feature concerns a different kind of passage, from the Bi Shu Shan Zhuang through Jin Shan Mountain toward a celestial universe and toward landmarks of Jiangnan. The Kang Xi Emperor explains this feature in two of his poems on the scenery viewed from the Jin Shan Mountain. The title given to plate 18 suggests the idea of passage, since 'Tian Yu Xian Cheng' may also be translated as 'In the sky and cosmos it passes entirely unimpeded.' 20 Both the vista's name and the temple's name ( $\mathrm{Pu} \mathrm{Le}$ ) imply that Qian Long conceived the passage from Jin Shan Mountain through Pu Le Temple to Chui Feng Peak as an axis for 'universal joy,' which is of one of the three ways of achieving Buddhahood. The Kang Xi Emperor repeated these same ideas in the poem he wrote on the Tian Yu Xian Cheng vista. He insisted on distance, passage, connection and extension as the beneficial characteristics of the Jin Shan Mountain:

In the middle of the lakes stands a peak; its summit has a terrace with three buildings on it; to the north is the god's pavilion; its top is connected to the clouds; its bottom is adjacent to water. It looks as if the climb to Miaogao peak, the hazy clouds of Beigu, and the wind and moon of Haimen are all encompassed in one look. With rosy clouds as its background, the storied pavilion should be a hermit's home. The human world is far away from this magnificent place. ${ }^{2 .}$

\section{Garden and geography}

A thorough analysis of the built landscape of the Qing summer capital would explain how gardens were designed to serve as a metaphorical passage between landscape layers, from reduction of the imperial landscape to enlargement of the Buddhist landscape. These two accounts of landscape-making refer to two spatial orders, one Confucianist, geographical, objective and exhaustive description of the outside world, the other Buddhist, metaphysical, subjective and a negation of the first order. This second order opens a passage outside the illusions of the physical world. The texts, annotations, vista titles and landscape miniatures of the Album of Imperial Poerns introduced a succession of garden vistas in time, not a sequence of garden vistas in space. The perspectives of the garden scenery were composed to offer alternating views of landscape for observers as they moved through the chronological sequence of 36 vistas. The vistas were indeed designed to be nothing more than instants of totality on a circuit of landscape transition. The court gardens of the Bi Shu Shan Zhuang have elicited a strong aesthetic response frora visitors but one cannot generally assume that gardens outside the Bi Shu Shan Zhuang had no importance for the Manchu landscape spectacle. One cannot analyse court gardens without referring to the local morphology, the architectural context or the cultural notions of spatiality that directed their design. Research conducted on the lake district gardens of the Bi Shu Shan Zhuang should also include the landscape of the surrounding districts if one wants fully to appreciate the quality of wholeness intrinsic to the inclusion of buildings and gardens inside the $\mathrm{Bi}$ Shu Shan Zhuang. A characteristic feature of traditional landscape architecture in China, this wholeness resulted from a desire for confusion between natural landscape and naturalized landscape, a confusion implicit in the Album of Imperial Poems' description of the Bi Shu Shan Zhuang. ${ }^{2.2}$

The gardens of Chengde reveal an order articulated on the natural landscape by an all-encompassing conception of power. The patterns that organized these gardens spatially manifested three characteristics. First, the garden vistas and villa compounds refused to be reduced to one another to form a coherent landscape, and used techniques that played with distance and composition. Second, the ultimate rationale of these gardens resided in the architectural semiology of their political message, and not in their morphological layouts or functional types. Qing illustrations, indeed, 
betrayed an underlying concern for the dislocation of the spatial unity of the place. Finally, the Bi Shu Shan Zhuang buildings were modeled on architectural styles from throughout the Qing Empire. In short, the cultural geography of the imperial landscape of Chengde was instrumental in separating the gardens, as cultural expressions, from their physical setting and geographical locations. Similarly and at a different scale, the geography of Chengde deported, isolated and enclosed features from celebrated places in the empire.

The Bi Shu Shan Zhuang served as a microcosmic representation of the geography of the Manchu Empire. Within the walls of the Bi Shu Shan Zhuang one can examine the modalities of interaction between a Jiangnan landscape in the south of the imperial residence and a Mongol-type landscape in the north, and between the religious landscape in the Tibetan east and the natural frontier landscape of the Manchu west. The mundane and religious gardens that surround the Bi Shu Shan Zhuang must moreover be considered in the larger environment of the simultaneous interaction between empire and Chengde. The garden features of the prefecture of Chengde were derived from the frontier region of northern China, while those of the Bi Shu Shan Zhuang recalled the cities of Jiangnan, and those of the Wai Ba Miao temples referred to a metaphysical order and to a distinct Tibetan landscape architecture. The garden complexes dotting the landscape of Chengde participated in defining the many facets of a relationship that combined landmarks of the Manchu Empire such as Zhenjiang, Beijing, Mukden and Lhasa. Court paintings and daily records of the monarchs' activities have demonstrated that the gardens of Chengde provided one of the most desired settings for the conduct of administrative and religious affairs of the most populous empire of the eighteenth century. In their common suggestion of landscape continuum, the gardens of the Bi Shu Shan Zhuang and those of the Wai Ba Miao temples both negated the objective existence of the frontier landscape.

The Chengde gardens were meant to create a place where the subjective and the objective would be merged, where intention would be fused with realization, and where landscape would be reduced to garden. Jin Shan Mountain exemplified this wholeness because it was the meeting place of three axes of landscape transition. In the interpretation of these gardens one sees how axes, landforms and location were in agreement with the crientation criteria of the topomantic landscape. The mapping of the axes of landscape transition that passed unimpeded through Jin Shan Mountain reveals how precise symbolic features accommodated political and religious spatial organizations. A horizontal north-south axis connected the Jin Shan of natural Manchuria to the Jin Shan of cultural Jiangnan. Located in the north, the Manchurian Jin Shan Mountain occupied the honorific place where it received yang influences; the Chinese Jin Shan Temple occupied a subordinate southern place and was placed under yin influences. A horizontal west-east axis connected Ru Yi Island, symbol of the sovereign's rule, to the Jin Shan pagoda, the Pu Le Temple mandala, and, beyond, to Chui Feng Peak, itself a possible symbol of Mount Sumeru (figure II). Ru Yi Island is in the yin western position, whereas Chui Feng Peak lies in the yang eastern position. Qian Long ordered the building of the Sumeru Temple of Chengde north of the residence and facing south in a yang position. A vertical axis through the round Jin Shan pagoda allowed cosmic energy to circulate freely between the mountain manor lake gardens and celestial universe, between the yin of Earth and the yang of Heaven.

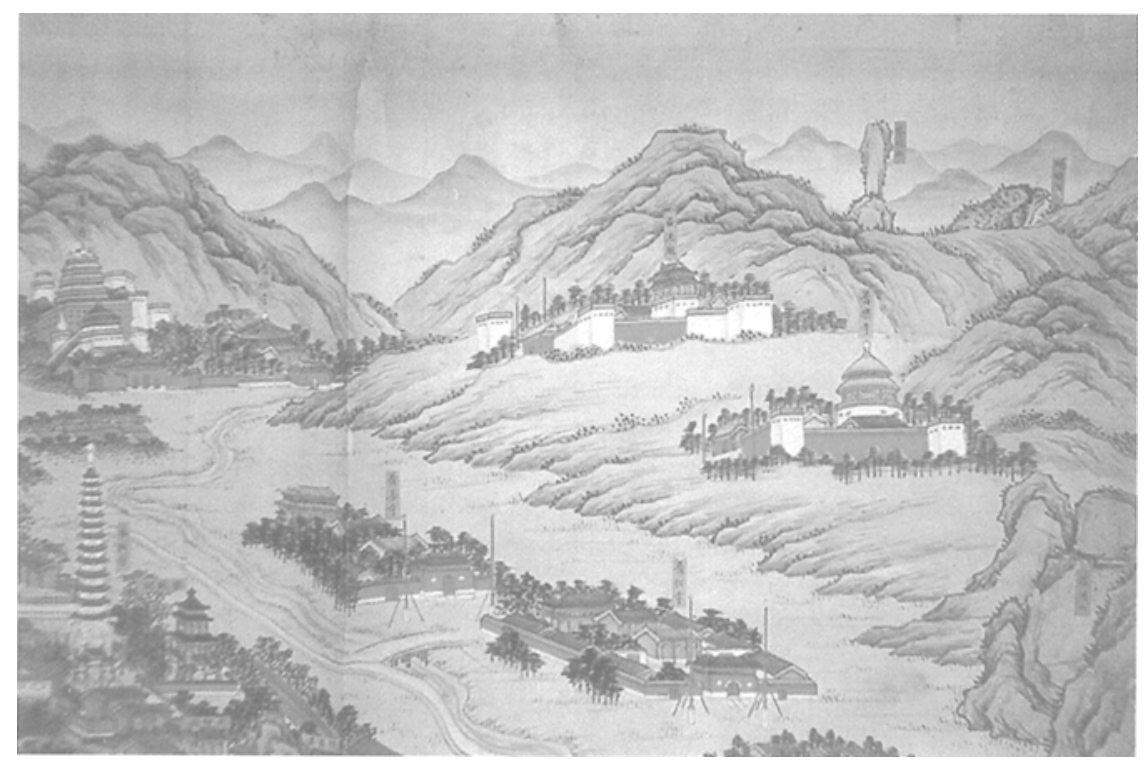

FIgURE II. The Alignment of $P u$ Le Temple and Qing Chui Peak; from Rehe xing gong quan tu (detail). Courtesy: Library of Congress. 


\section{Representation and imperial design}

The spectacle of the mountain manor gardens engendered 72 poems that served to complete the aestheticism of the Bi Shu Shan Zhuang. The Kang $\mathrm{Xi}$ Emperor selected 36 vistas and pavilions and gave a four-character name to each of them. These names served as titles for the 36 poems he wrote in I.7II. Kang Xi wrote that the peaceful vistas of the Bi Shu Shan Zhuang helped him in understanding human nature and reinforced his Confucian love for the people. ${ }^{23}$ Accompanied by plates of the vistas, the Kang $X_{i}$ Emperor's poems were published by the Qian Long Emperor, in separate but strikingly similar Manchu and Chinese versions. When Qian Long toured his grandfather's circuit of vantage points in $174 \mathrm{I}$, he was so moved by the scenery that he wrote a second series of poems using the same rhyme pattern. Fifteen years later he in his turn selected 36 places inside the Bi Shu Shan Zhuang as a background for his own series of poems. Qian Long's 36 vistas added to Kang $\mathrm{Xi}$ vistas make a new series of 72 vistas. Out of deference to the Kang $\mathrm{Xi}$ Emperor, he gave his vistas names of three characters only. The Qian Long Emperor's interest in gardens was directly linked to his pretension of acting as a scholar who was equally gifted in poetry, calligraphy, bibliophilia and landscape architecture. His open pavilions were the locale for poetic discussion of nature, inspired by mist and springs, bamboo and pines, cliffs and vistas. The Qian Long Emperor himself amply justified the use of scholars' gardens for re-creating in the imperial gardens of Chengde the emotions aroused by the Jiangnan landscape. Qian Long detailed the rationale for the construction of the Bi Shu Shan Zhuang gardens when he justified his huge investment in Confucian terms: serve the people, follow historical precedents, and act with restraint:

Every emperor and ruler, when he has retired from audience and has finished his public duties must have a garden where he may stroll and look about and relax his heart. If he has a suitable place to do this, it will refresh his mind and regulate his emotions, but if not, he will become engrossed in sensual pleasure and lose his will power. ${ }^{24}$

In the gardens of Chengde all opposition between the many landscapes of the empire were reconciled to form under imperial supervision the Qing landscape. The new cultural hearth of a new non-Chinese dynasty was located away from Beijing's Forbidden City and inside the Bi Shu Shan
Zhuang at the site of the Jin Shan Mountain, which dominated the geography of Chengde gardens. The significance of the Chengde gardens does not, therefore, reside in the juxtaposition of landscape architectural models developed elsewhere in the cultural cores of the Qing Empire. It lies instead in the synthesis achieved of cultural and natural environments as a spectacular aspect of the Manchu 'Great Enterprise.' Chengde gardens are particularly attractive because of the misleading harmony that results from the Qian Long Emperor's popularization of a constructed landscape that appears to be natural. The strong contribution of topography, its 'male' vigor, is moderated with the introduction of 'female' lakes at the foot of the mountain district. To this geomantic treatment the Qian Long Emperor added a series of architectural metaphors and allusive place names that constituted multiple layers of landscape understanding. The physical stratum that formed the palace, garden, prairie and mountain quarters of the imperial residence, the microcosmic stratum that was an enlarged multidimensional map of the Manchu empire, and a macrocosmic stratum with elements suggesting the representation of a Buddhist cosmos combine to form these geographical layers.

The contribution of the gardens of Chengde to the functioning of the imperial society around the emperor could be analyzed according to the efficiency of the visual, textural, sensorial, emotional and intellectual modes of propaganda if there were sources that helped in defining this efficiency. The targets of this garden propaganda included the emperor, ambassadors, vassals, priests and commoners, and were clearly identified. The audience that the Qian Long Emperor summoned at his court was segmented but was not allowed to respond in divergent ways to his garden politics. The Tibetan clergy and Manchu-Mongol bannermen remained silent, apparently; as Tibetan sources have little to say about Chengde. Few Chinese officiais would have dared to imagine the hidden cost of this garden monument erected to glorify Manchu dynastic policy in Central Asia. It is not known if the vassal and ambassadors from Central Asia were impressed by the Wanshu yuan prairie of the $\mathrm{Bi}$ Shu Shan Zhuang, where Qian Long used to receive and entertain them. ${ }^{25}$ All one can suppose is that, when summoned to Qian Long's court, they probably were all able to make similar comparisons between the gardens of Chengde and the gardens they were familiar with.

The court abandoned the Bi Shu Shan Zhuang in 1820 , which was a crude comment on Qian Long's garden policy. The unauthorized appropriation 
of the natural resources of the Chengde prefecture occurred during the nineteenth century through the illegal immigration, deforestation and poaching that accompanied the sinicization of the Mongol lands north of the Great Wall. The Manchu strategy of ethnic submission was totally subverted after the fall of the Qing. The buildings of the temple on Jin Shan were extensively damaged soon after $191 \mathrm{I}^{26}$ The palaces of the Bi Shu Shan Zhuang and the temples of Wai Ba Miao were alternatively plundered and neglected by the governors of Republican China (I9II-49) and the Maoist administration (1949-76). Scientific survey and restoration of the Bi Shu Shan Zhuang were conducted by the Japanese-led Manchoukouo regime (1935-45) and the Dengist administration (1978-97). The result of the ambitious campaign of restoration of the early 1980 os has been the opening of the Outer Temples and the transformation of the gardens of the Bi Shu Shan Zhutang into a public park and museum. During part of the twentieth century the message carried by the Chengde gardens has been one of union of ethnic minorities around a political regime, which after all was one of the goals of Qian Long's policy. For almost 20 years now, restored Chengde has been the major tourist attraction of Northern China outside Beijing. In I995 the Bi Shu Shan Zhuang and the Outer Temples became a World Heritage site internationally recognized for its historical significance.

Today's understanding of how garden representation has effectively influenced the perception of the Bi Shu Shan Zhuang that Qian Long expected might surprise the emperor as it has remained largely unaffected by what he wished the contemporary viewers of the Chengde gardens to see. I cannot pretend to have had privileged access to Qian Long's intentions and do not claim any advance on scholars such as Yang Tianzai and Meng Zhaozhen who have carefully studied the literary and architectural legacies of the Bi Shu Shan Zhuang. ${ }^{27}$ I note, however, that Qian Long's audience, already invisible in the paintings, vistas and maps, almost always remained sulent in written records. Lack of material unfortunately prevents the comparison of the emperor's position on how the imperial gardens of Chengde should be received to the actual social response to the spectacle of power displayed in Chengde. The absence of independent accounts of the gardens by Qing subjects may be seen as evidence of the effectiveness of imperial censorship and, if it is the case, would imply that the emperor himself was the cause of the discrepancies that I have found in the examination of the pictorial records on the gardens. The problem with this argument is that Qian Long's degree of control on garden representation is difficult to assess with certitude. Furthermore, what is seen now as discrepancy may not have been understood as such by the emperor. I have taken the risk of attributing a rationale to something that may not have existed because I have been perplexed by the precision and coherence of the 1780 pictorial materials on the Bi Shu Shan Zhuang.

It may still be safe to conclude that Qian Long's imperial conception of space and the cohesive force of his vision enabled the cultural landscape of Chengde to reconcile the diverse components imported into the summer capital's gardens. The geographical provenance of the imperial residence's gardens was evident enough that visitors to the court would have recognized the Bi Shu Shan Zhuang as an imitated version of their own home landscape, transported to Chengde from Mongolia or Jiangnan. After pictorial treatment and publication of the Chengde Gazetteer, these gardens acquired moreover a meaning they did not have in their previous environments: the printed garden vistas articulated and legitimized the Qian Long Emperor's fixed images of his political supremacy that the readers of the Chengde Gazetteer were given to contemplate. The gardens of Chengde turned Qian Long's mountain manor into an empire. By building imperial gardens north of the Great Wall and reprinting garden iconography for a Sino-Manchu readership the Qing emperor implicitly rewrote the history of the conflictual relationship between the Han Chinese and Central Asian dynasties. The Chengde gardens celebrated the official reconciliation of the ethnic identities of China and Central Asia and enlarged the space of ambiguity, manipulation and disappearance that the emperor felt he needed for better governance of both sides of the Great Wall.

University of Oklahoma
NOTES

1. Although my idea of representation is a conventional one and has not been influenced by the work of postmodern geographers, the general argument, that discrepancy in visual records may deserve a geographical analysis, is relatively new and owes a lot to Mark Monmonier's innovative approach to map analysis; MARK MonmonIER, How to Lie with Maps (Chicago: University of Chicago Press, 1996); idem, Drawing the Line: Tales of Maps 
STUDIES IN THE HISTORY OF GARDENS AND DESIGNED LANDSCAPES : FORET

and Cartocontroversy (Henry Holt, 1995). To a degree, this paper on the garden representation intended by the Qian Long Emperor, and the disappearance of certain garden features (pivotal mountain temple, walls, people), is the development of several points have made in 'Garden and Mountain Rhetoric,' a chapter of my Mapping Chengde: The Qing Landscape Enterprise (University of Hawai'i Press, 2000). For more information about the creation of a political landscape in Chengde and the cosmological interpretation of Jin Shan mountain, see my 'The Manchu landscape enterprise', Ecumene, II/3 (1995), pp. 325-34. My first analysis of the Bi Shu Shan Zhuang had landscape history as its focus and was published in French: 'La formation du paysage impérial mandchou', Géographie et Cultures, vi (1993), pp. 84-104. For having shared their ideas with me, I thank Stanislaus Fung, University of New South Wales, an anonymous reviewer of the journal and Corinne A. Pernet, University of Oklahoma.

2. This is an excerpt of the translation from Manchu that Mark Elliott has proposed. The full bibliographic reference is QING SHEngzu (Kang Xi Emperor) Han-i araha Alan-i tokso de halhin be jailaha gi bithe (Chinese title: Yu zhi Bi Shu Shan Zhuong shi [literally Imperial Poems on the Bi Shu Shan Zhuang]) (Chengde or Beijing, I74I). The preface to the poems on the Bi Shu Shan Zhuang is credited to the Kang Xi Emperor, and it would seem that the Chinese version does not predate the Manchu version of the Preface of the Yu zhi Bi Shu Shan Zhwang shi. MARK ElLIOTT and Scott Lowe, 'Preface to the thirty-six views of the Bi Shu Shan Zhuang: record of the Mountain Manor to Escape the Heat', in The Realm in Miniature eds RUTH DUNNELL, MARK Elliott, Philippe Forêt and James Millward (Honolulu: University of Hawai'i Press, forthcoming)

3. The theoretical issues linked to the garden representations of the Bi Shu Shan Zhuang are, o course, not entirely specific to Chengde and Qian Long. The historians of Chinese garden architecture have raised issues similar to the ones discussed here about center, nature, coherence and naming. On space and time as related interpretive constructs, see David L. Hall and Roger T. Ames, 'The cosmological setting of Chinese gardens', Studies in the History of Gardens and Designed Landscapes, $\mathrm{XVIII} / 3$ (I998), pp. $175-86$. On naming in gardens, see John MaKkHaM, 'The Confucian role in names in traditional chinese gardens', Studies in the History of Gardens and Designed Landscapes, xviII/3 (I998), pp. I $87-2 \mathrm{~T}$.

4. The gardens were designed to represent a miniaturized model of the Qing empire. At the same time the garden landmarks and landforms were organized to suggest an invitation to move into the transcendental cosmology of Buddhism. ANNE CHAYET, Les temples de Jehol et leurs modèles tibétains. Synthèse I9 (Paris, Recherche sur les Civilisations, I985), p. I03. Pictures of the Chengde gardens as they appear today can easily be found in books sold to tourists such as Chengde Bi Sim Shan Zhuang Wa $\mathrm{Ba}$ Miao quan jing tu (A Panorama of Mountain Resort and Eight Outer Temples in Chengde) (Shijiazhuang: Hebei renmin chubanshe, 1993)

5. The Yu zhi Bi Shu Shan Zhwang shi or Yu zhi Bi Shu Shan Zhuang tu yons album [hereafter Album of Imperial Poems] consists of a collection of 36 placenames, each with a poem by the Kang Xi Emperor, an erudite commentary and the engraving of a landscape vista. The poems were first written in I7I2 in Manchu and Chinese. The Album of Imperial Poems was reprinted after the Qian Long Emperor added another 36 poems to the series of 36 poems composed by his grandfather. Seventy years later Qian Long let the preface and the album of poems and vistas become part of the Chengde Gazetteer. All the editions have the same woodblock illustrations. The album was offered to the Qian long Emperor's guests in the Bi Shu Shan Zhuang.

6. The maps of Chengde are geometric in the sense that they are constrained by a grid system of distances but they do not have a constant scale and are not astronomically based, as modern topographical maps are, in the sense that the prefectur maps do not refer to any projection system. The maps consulted in the Chengde Gazetteer (Chengde fu $z h i$ of Rehe $z h i$ ) are the following:

Bi Shu Shan Zhuang zong tu ("Comprehensive Map of the Montain Manor to Flee the Heat), juan 25 , xinggong I.

Chengde fu quan iu (General Map of the Chengde Prefecture), juan 49, jiancheng I.

Chengde fu tu (Map of the Chengde Prefecture), juan 49, jiancheng 2.

Kalahetun xing gong (Kalahetun Hunting Lodge) juan 43, xing gong $\mathrm{r} 9$

Wei chang quan " (General Map of the Mulan Hunting Grounds), juan 45, Weichang I.

The source of these maps is HaI ZHONGXIU and Ling Congshang (eds), Chengde fu zhi (Chengde. Gazetteer) Zhongguo fangzhi congshu saibei difang, I7 (rep. Taibei: Taibei changwen chubanshe, 1968). The title of the $178 \mathrm{I}$ edition was Qin ding Rehe zhi. Later editions appeared under different titles Chengde fu zhi in 1830 and Rehe tong zhi in I 888. The full bibliographic references of the two landscape paintings of the mountain manor of Chengde are Rehe xing gong quan tu (Complete Map of the Hunting Lodge of Chengde) (Washingtoll, DC: Library of Congress, 7824 C53A3 I $7-\mathrm{J} 4$ ); and Tai uan di li tu (Map of the Geography of the Bay of Terraces) (Washington, DC: Library of Congress, 7824 C53A5 $17-J 4$ )

7. Anne Chayet, Les temples de Jehol et leurs modèles tibétuitus, figure 4 , may be completed with information provided by Hou Renzhi in his map of the Bi Shu Shan Zhuang, published in Beijing lishi dituji, map 49-50. Hou ReNZHI (ed), Beijing lishi dituji (Historical Atlas of Beijing) (Beijing: Beijing lishi dituji bianweihus, I985).

8. PAK JIWON, Rehe ri $j i$ (Diary of Chengde), ch. Ió. See Eugen Feifel's translation in 'Pak Jiwon: Huan-hsi, magic entertainment in Jehol', Oriens Extremus, $\operatorname{xIX}(1972)$, p. I43. 
9. Chengde fu zhi, p. 414. Hou RenzHI, Beijing lishi dituji, pp. 49-50.

10. Geoffrey R. Waters, Three Elegies of $C h$ 'u: $A n$ Introduction to the Traditional Interpretation of the Ch' $u$ $T z^{\prime} u$ (Madison: University of Wisconsin Press, 1985), pp. 34-7.

it. William Soothill and Lewis Hodous, $A$ Dictionary of Chinese Buddhist Terms (London: Kegan Paul, Trench, Trubner \& Co., Ltd, 1937), p. 394 .

12. Seven Jin Shan Mountains plus one Sumeru Mountain make only eight mountains; the ninth one is an iron wheel mountain that encompasses all the mountains of the archetype. Jin Shan also designates the Golden Buddha.

I3. I am contrasting here the mountain of Jin Shan to the temple of Jin Shan. For better clarity I will use 'Jin Shan Mountain' and 'Jin Shan Temple' when discussing the dual significance of Jin Shan.

I. KANG XI, Rehe zhi, II, p. 825 (my translation).

I5. The Zhongouo gujin diming da cidian dictionary lists I2 Jin Shan place names. ZaNG LiHe (ed), Zhongguo gujin diming da cidian (Hong Kong: Shangwu yinshuguan, 193I), pp. 538-9.

i6. Chayet, Les temples de Jehol et leurs modèles tibétains, p. 69.
THE IMPERIAL GARDENS OF CHENGDE

17. Otto Franke, Beschreibung des Jehol-Gebietes in der Provinz Chihli. Detailstudien in Chinesischer Landes- und Volkskunde (Leipzig: Dieterich'sche Verlagsbuchhandlung Theodor Weicher, 1902), p. 93 .

18. Chayet, Les temples de Jehol et leurs modèles tibétains, p. I35, n. I 37 .

19. Soothill and Hodous, A Dictionary of Chinese Buddhist Terms, p. 156.

20. Tian Yu Xian Cheng, p. 18 (In the sky and cosmos entirely it passes unimpeded) Yu zhi Bi Shu Shan Zhuang tu yong, pp. 48-50. Franke, Beschreibung des Jehol-Gebietes, pp. 91, p. 93.

2r. KANG XI, Yu zhi Bi Shu Shan Zhuang shi, 'Tian yu Xian Cheng' plate (my translation). The place names quoted by Kang $\mathrm{Xi}$ in the introduction are all in Jiangnan.

22. TAdASH SeKino, Summer Palace and Lama Temples in Jehol (Tokyo: Kojusai Bunka Shinkokai, I935) p. 9; Tadashi Sekino and Takeshima Takurchi, Nekka. Jehol. The most Glorious and Monumental Relics in Manchoukouo. Tokyo Institute, Academy of Oriental Culture (Tokyo: Zauho, 1934).

23. Kang XI, Rehe zhi, II, p. 826 .

24. Qian Long's introduction to Yu zhi Yuan Ming Yuan tu yong; CARroll MALONE, History of the
Peking Summer Palaces under the Ch'ing Dynasty. University of Illinois Bulletin 3 I (Urbana-Champaign: University of Illinois, 1934), p. 64 .

25. Lord Macartney who led the British embassy to China in $1793-94$ kept a journal of his guided visit of Chengde, and garden historians may find his reactions to the gardens noteworthy. J. L. Cranmer-Byng (ed), An Embassy to China. Being the Journal Kept by Lord Macartney during his Embassy to the Enperor Ch'ien-lung, I793-I794 (London: Longmans, 1962), pp. 125-6.

26. TADASHI, Summer Palace, figure 6, 'Chin-shan Ssï in the Imperial Park in I909' and figure 7, 'Chin-shan Ssü in I933.'

27. Meng Zhaozren, Bi Shu Shan Zhuang yuanlin yishu (The Garden Art of the Bi Shu Shan Zhuang) (Beijing: Zijincheng chubanshe, 1985). Yang TianzaI, Bi Shu Shan Zhuang beiwen shiyi (Annotations on the Stelae of the Bi Shu Shan Zhuang) (Beijng, Zijincheng chubanshe, 1985). For an exhaustive architectural survey of the gardens, buildings and temples of Chengde see TIanjIN DAXUE JIANZHUXI and ChENGde SHI WENWUJu (eds), Chengde gu jianzhu (Ancient Architecture of Chengde) (Hong Kong: Joint Publ. and Beijing: Zhongguo jianzhu gongye chubanshe, 1982). 